\title{
Reactive Power Management for Distributed Generation: Motivation and Solutions
}

\author{
Therese Uzochukwuamaka Okeke and Ramy Georgious Zaher \\ University of Oviedo, Spain
}

\begin{abstract}
With the growing concerns of economical and environmental issues arising from centralized electrical generation, transmission and distribution (GTD), distributed generation (DG) has become of high interest to help reduce these impacts. However, most machines (electric generators) used in DG are induction motors (asynchronous) which have some limitations that cannot be overlooked. One limitation is the shortage of reactive power needed to maintain the voltage required to deliver active power. Despite this limitation, technical advancements have been made in the use of power electronic converters to obtain reliable and secure operations of power system. Various means of reactive power compensation in DG and its utilization are discussed in this paper.
\end{abstract}

Index Terms - Centralized Electrical GTD, Distributed Generation (DG), Reactive Power

\section{INTRODUCTION - DISTRIBUTED GENERATION}

$\mathrm{D}$ ISTRIBUTED generation is used to describe relatively small-scale generators that produce several kilowatts $(\mathrm{kW})$ to tens of megawatts (MW) of power and are generally connected to the grid at the distribution or substation levels. In the last decade, technological innovations and a changing economic and regulatory environment have resulted in a renewed interest for distributed generation [1]. This is confirmed by the IEA (2002), who lists five major factors that contribute to this evolution, i.e. developments in distributed generation technologies, constraints on the construction of new transmission lines, increased customer demand for highly reliable electricity, the electricity market liberalization and concerns about climate change.

Despite the evolution, some issues arise when these units are connected to distribution power system, which includes power quality, proper system operation and reactive power management. Power electronic converters, as discussed in this paper, have been ascertained to resolve issues mentioned above.

\section{RENEWABLE RESOURCES IN DISTRIBUTED GENERATION}

\section{A. Renewable resources availability}

An overview of the earth's main energy paths that can be harnessed to generate sustainable electricity is shown in table 1.0. It is apparent that the main source is the sun. On average the rate of solar radiation intercepted by the earth's surface is about 8000 times as the average rate of world primary energy consumption. The table shows that this energy flux can be accessed directly using solar thermal or photovoltaic (PV) technology, or indirectly in the form of wind, wave, hydro and biofuels. The others are also regarded as renewable but it is only a small fraction of that available from the sun.

Table 1. Renewable Energy (RE) flow paths

\begin{tabular}{|l|l|l|}
\hline Source & Path & Renewable Energy \\
\hline \multirow{3}{*}{$\begin{array}{l}\text { Sun (about } \\
\text { 120,000 TW } \\
\text { absorbed by } \\
\text { the earth }\end{array}$} & Direct heating & Thermal electric \\
\cline { 2 - 3 } & Direct radiation & Photovoltaics \\
\cline { 2 - 3 } & Water evaporation & Hydropower \\
\cline { 2 - 3 } & Atmosphere heating & Wind/Wave \\
\cline { 2 - 3 } $\begin{array}{l}\text { Gravitational forces (Moon-sun)- } \\
\text { 3TW }\end{array}$ & Tidal schemes \\
\hline Earth's core-10TW & Geothermal schemes \\
\hline
\end{tabular}

A substantial proportion of the incident radiation is reflected back to space. Before the onset of industrial revolution, energy inputs and outputs have been in equilibrium at a temperature suitable for the development of the earth's biosphere. Hence, exploiting this incident energy through the application of renewable energy technology does not disturb this balance [2].

\section{B. Motivation for its use}

Renewable energy (RE) can in principle provide all the energy services needed, although with some difficulty and cost. However, it has the advantage that being a naturally distributed resource, it can also provide energy to remote areas without the need for extensive energy transport systems. $\mathrm{RE}$ is currently experiencing dramatic growth, with various Nations discussing the environmental issues arising from conventional electricity generation and transmission, which is basically global warming. Another critical reason for promoting renewable energy is to reduce dependence on energy imports. Countries in Europe for example, promote RE for both reasons stated above. EU leaders reached an agreement in 2007 stating that $20 \%$ of its final energy consumption should be produced from RE by 2020 as part of its drive to cut emissions of $\mathrm{CO}_{2}$. Although, it might not have been fully achieved, it shows that various policies are being effected to drive RE. The table below shows an increase in percentage gross final energy consumption [3].

Table 2. Share of RE (in \% of gross final energy consumption)

\begin{tabular}{|l|l|l|l|l|l|c|}
\hline Year(from 2006) & $' 06$ & ${ }^{\prime} 07$ & ${ }^{\prime} 08$ & ${ }^{\prime} 09$ & $' 10$ & 2020 goal \\
\hline EU Consumption & $\mathbf{9 . 0}$ & $\mathbf{9 . 9}$ & $\mathbf{1 0 . 5}$ & $\mathbf{1 1 . 7}$ & $\mathbf{1 2 . 4}$ & $\mathbf{2 0}$ \\
\hline
\end{tabular}


A graphical representation of the table above:

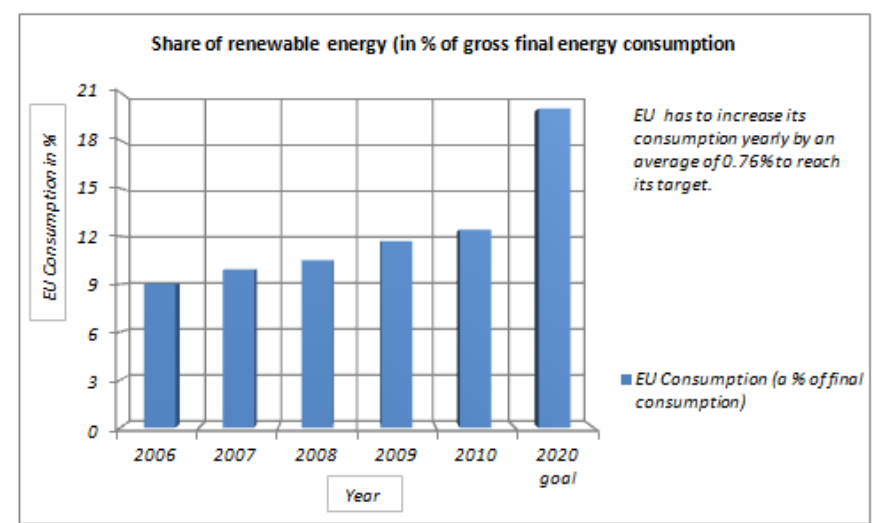

Figure 1. Graphical representation of EU RE share.

\section{Drawbacks of RE}

The fastest growing RE technologies are solar photovoltaics and wind energy. However, one characteristic they share is their variability and relative unpredictability. This presents a challenge in integrating such sources in distribution networks that have been designed to operate with conventional generators whose availability appears certain. This characteristic, however, can be stabilized with the use of Power Electronic Converters in the system, which will allow for onward dispatch to the grid.

Another major drawback is the absorption of Reactive Power in generators used in converting mechanical energy to electrical energy.

\section{Generator Usage In RE TeChNOlogy}

There are basically 2 types of generators that can be used to convert mechanical energy to electrical energy and they are synchronous and asynchronous generators. Both generators have considerable advantages and disadvantages but due to cost associated with the size of a generator and the complexity in designing synchronous generators, - since a generator must match the amount of rotational energy produced from kinetic energy, - Asynchronous (or induction) generators are preferred because of its rotor design. Hence, the choice of using an induction generator introduces reactive power loss.

An induction generator is a source of Active Power but a sink of Reactive Power [4]. A considerable amount of Reactive Power is still drawn to magnetize its iron core even when Active Power output is zero. As increasing torque is applied to generate Active Power, extra Reactive Power is absorbed due to that consumed by the series reactance. If DG is connected to the grid, then absorption of Reactive Power will have an adverse effect on the grid. And when there is not enough reactive power, the voltage sags down and it is not possible to push the power demanded by loads through the lines

\section{Importance Of Reactive Power In A System}

Alternating Current (AC) has an alternating voltage characteristic that makes it advantageous to use in power systems. In an AC circuit, energy storage elements (inductance and capacitance) may result in periodic reversals of the direction of energy flow. This direction of energy flow produces Active Power which is the portion that is averaged over a complete cycle of the AC waveform; and Reactive Power which is produced due to the stored energy and returned to source of generation (and not to the load) in each cycle.

Despite the non-usefulness of Reactive Power in transferring energy to the load, voltage control is dependent on it to drive adequate Active Power.

\section{Theorem: Voltage Magnitude and Reactive Power}

In a no-loss line, active power $\mathrm{P}$ is same at any point of the line:

$\mathrm{P}_{\mathrm{S}}=\mathrm{P}_{\mathrm{r}}=\mathrm{P}=\left[V * \cos \left(\frac{\delta}{2}\right)\right] \cdot\left[\frac{2 V * \sin \left(\frac{\delta}{2}\right)}{X}\right]=\frac{V^{2}}{X} \sin (\delta)$

Reactive power at sending end is opposite of reactive power at receiving end:

$\mathrm{Q}_{\mathrm{s}}=-\mathrm{Q}_{\mathrm{r}}=\mathrm{Q}=\left[V * \sin \left(\frac{\delta}{2}\right)\right] \cdot\left[\frac{2 V * \sin \left(\frac{\delta}{2}\right)}{X}\right]=\frac{V^{2}}{X}(1-$ $\cos \delta)$

From the equations, as $\delta$ is very small, active power mainly depends on $\delta$ whereas reactive power mainly depends on voltage magnitude.

This is the basic reason why operators ensure that absorption of Reactive Power is minimized from the grid, to ensure there is enough to push adequate active power over the lines. With the adverse effect of using induction generators in RE, DGs are required to generate adequate Reactive Power to balance the grid and avoid voltage problems.

\section{Reactive Power Control On DG USING POWER FACTOR CORRECTION PRINCIPLE}

Since Reactive Power is needed to setup the rotating magnetic field in an induction generator, it could be imported from the grid. With the grid/lines issues raised, it is more economical to generate it locally. This can be achieved using Power Factor Correction (PFC) principle - bank of capacitors is used. PFC capacitors could be installed at the base of the system to generate the required Reactive Power which will bring the overall power factor close to unity. Most times, these capacitors are divided into sections to give room for independent switching, so that the Reactive Power generated can be adjusted to match that consumed by the induction generator as operating conditions change. This solution is greatly valued by the system operators since it will reduce losses on the transmission lines.

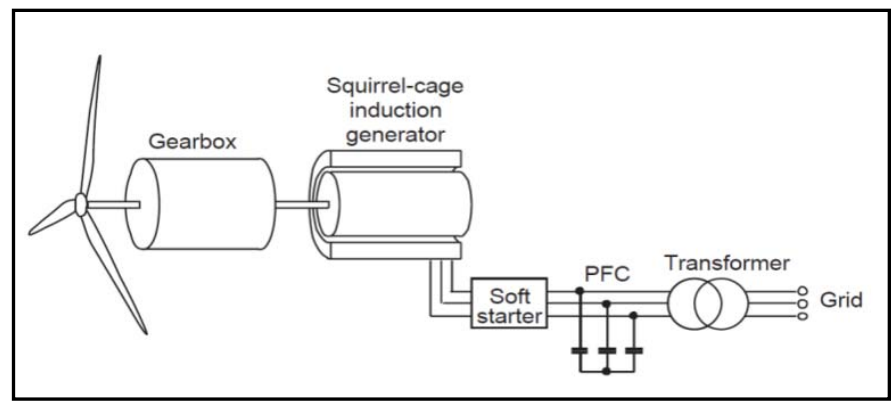

Figure 2. Squirrel-Cage Induction Generator with the PFC. 
Reactive Power control can be implemented using different techniques of PFC principle.

\section{Shunt Capacitors (Fixed AND Switchable)}

Because most appliances used have inductive components, they draw Lagging Reactive Power from the grid. To balance or cancel out this effect, capacitors are connected in parallel with the supply to draw Leading Reactive Power. It is apparent that the Leading Reactive Power is in the opposite direction of the Lagging Reactive Power. This method of connecting the capacitors in parallel is to allow the capacitance bank maintain a voltage rating that is same or a little higher than the system voltage.

In order to properly compensate the reactive power changes that occur in the system, the shunt capacitor may need to be switched on (or off) at load maximum (or minimum). This switching is apparently important to the success of this method because load will always vary. Different conventional methods can be used to control switched capacitors, such as time, voltage and reactive power [5].

\section{SYNCHRONOUS CONDENSERS}

A synchronous condenser is identical to a synchronous motor. Naturally, a synchronous motor loads a power line with a leading power factor (PF). To increase the PF further, the mechanical load is removed, hence, over-exciting its field. This shows that a synchronous condenser is intentionally designed to allow its shaft to spin freely [6]. Consequently, its purpose is not for energy conversion, but solely to adjust conditions on the grid. Its field is controlled by a voltage regulator to either generate or absorb reactive power as needed to adjust the grid's voltage, or to improve power factor. The main advantage with this control strategy is that reactive power generated can be continuously adjusted. It also has the capability of increasing current as voltage decreases to ensure adequate reactive power is generated, however, it increases its power losses [7].

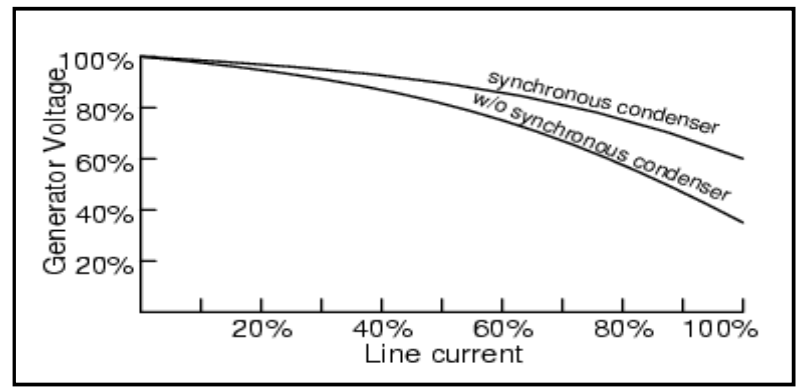

Figure 3. Synchronous Condenser improves voltage regulation (Source: All about circuits - Tony R. Kuphaldt) .

\section{STATIC VARS COMPENSATORS (SVC)}

An SVC is a shunt-connected VAR generator (or absorber) whose output is regularly adjusted to exchange capacitive or inductive current so as to control specific parameter of the electrical power system. This component is made from thyristors without gate turn-off capability. The operating principle and characteristics of thyristors makes SVC an automated impedance matching device, designed to bring the system closer to unity power factor. A typical one-line diagram of an SVC is shown below and it comprises [8]:

1. Thyristor-Controlled and Thyristor-Switched Reactor (TCR and TSR);

2. Thyristor-Switched Capacitor;

3. Harmonic Filter(s)

4. Mechanically switched capacitors or reactors (switched by a circuit breaker)

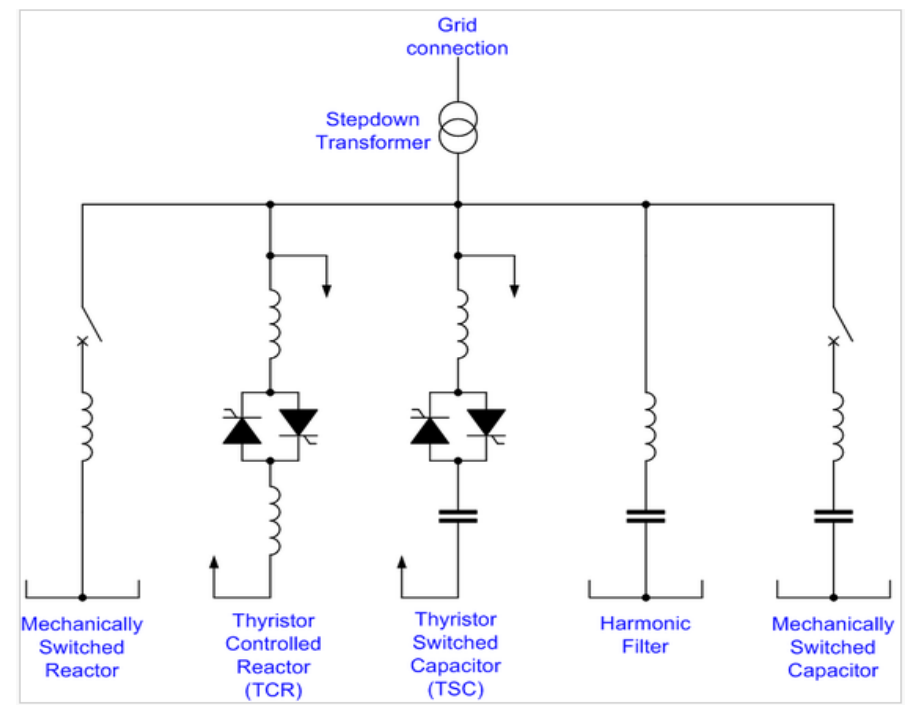

Figure 4. One-line diagram of a typical SVC configuration, employing TCR .

The switching of this device takes place in the sub-cycle timeframe (i.e., in less than 1/60 of a second), providing a continuous range of control. The range can be designed to span from absorbing to generating reactive power. Consequently, the controls can be designed to provide very fast and effective reactive support and voltage control. Because SVCs use capacitors, they suffer from the same degradation in reactive capability as voltage drops. They also do not have the short-term overload capability of synchronous condensers. SVC applications usually require harmonic filters to reduce the amount of harmonics injected into the power system.

\section{STATIC SYNChronous COMPENSATOR (STATCOM)}

The function of a STATCOM is similar to that of a synchronous condenser - the difference being the absence of inertia and its superiority in terms of better dynamics, lower investment cost and lower operating \& maintenance costs. A complete system basically consists of a DC voltage source, self commutated converters using Gate Commutated Turn-off (GCT) thyristors, and a step-up transformer [9].

The GCT thyristor has an improved gate structure and gate drive circuitry. This dramatically reduces the system operating losses due to the elimination of the snubber circuit. In contrast, the snubber circuit is required in the conventional switching operation of the GTO (Gate Turn-Off) thyristor, as well as IGBT devices. Consequently, fewer components, as well as lower losses, are achieved in the GCT-based converter application. Figure 1.4 shows the equivalent circuit of a STATCOM, where the GTO converter (with a DC voltage source) and the power system are illustrated as variable AC voltages. 


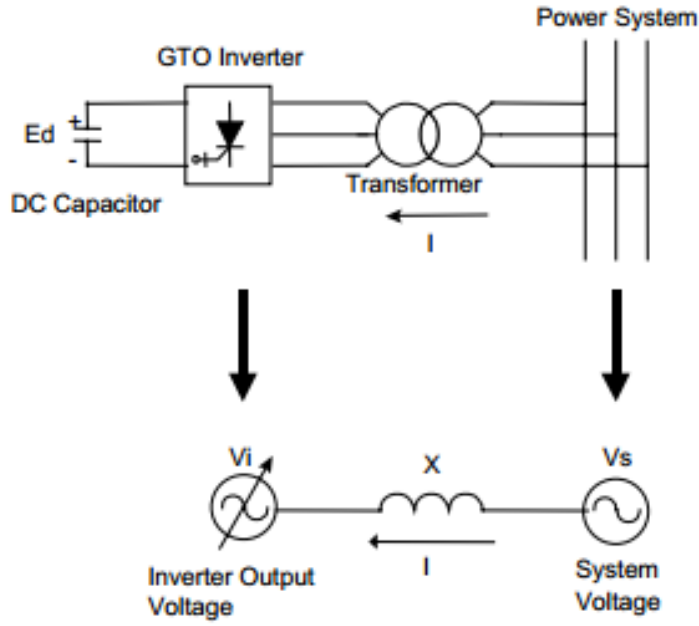

Figure 5. Equivalent circuit of a STATCOM.

The output voltage of the GTO converter $\left(\mathrm{V}_{\mathrm{i}}\right)$ is controlled in phase with the system voltage $\left(\mathrm{V}_{\mathrm{s}}\right)$ and the output current (I) varies depending on $\mathrm{V}_{\mathrm{i}}$. If $\mathrm{V}_{\mathrm{i}}=\mathrm{V}_{\mathrm{s}}$, then no reactive power is delivered to the system. Leading or lagging reactive power can only be produced when $V_{i}>V_{s}$ and $V_{i}<V_{s}$ respectively.

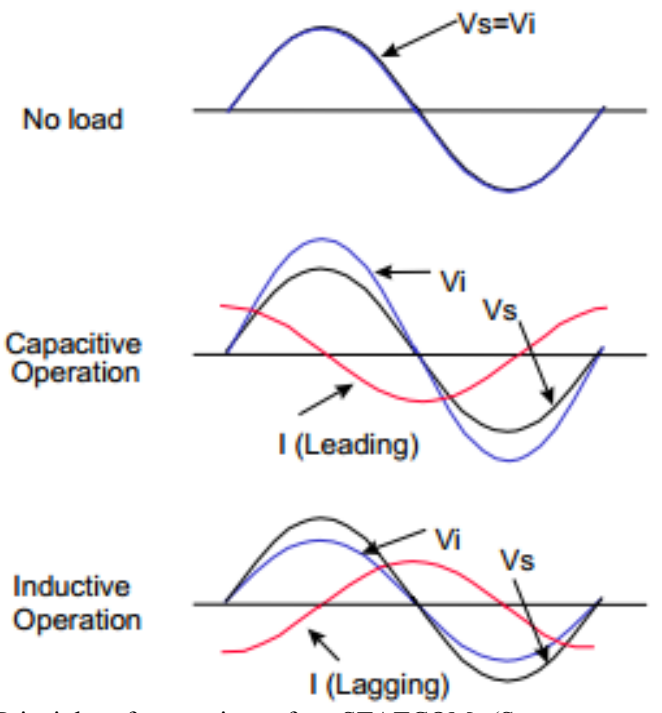

Figure 6. Principle of operation of a STATCOM (Source: Mitsubishi Corp).

The STATCOM smoothly and continuously controls voltage from $V_{1}$ to $V_{2}$, as shown in Figure 1.6. However, if the system voltage exceeds a low-voltage $\left(\mathrm{V}_{1}\right)$ or high-voltage limit $\left(\mathrm{V}_{2}\right)$, the STATCOM acts as a constant current source by controlling the converter voltage (Vi) appropriately. Thus, when operating at its voltage limits, the amount of reactive power compensation provided by the STATCOM is more than the most-common competing FACTS controller, namely the Static VAR Compensator (SVC). This is because at a low voltage limit, the reactive power drops off as the square of the voltage for the $\mathrm{SVC}$, where MVAR $=\mathrm{f}\left(\mathrm{BV}^{2}\right)$, but drops off linearly with the STATCOM, where MVAR $=f(V I)$. This makes the reactive power controllability of the STATCOM superior to that of the SVC, particularly during times of system distress.

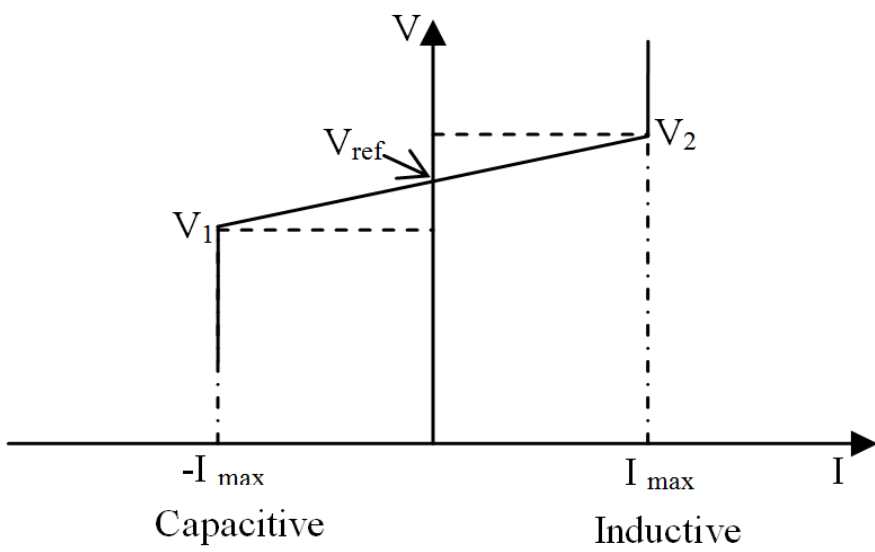

Figure 7. V-I characteristic of a STATCOM.

\section{SUMmARY AND CONCLUSION}

With the constraints attached to conventional means of power transmission and the advent of Distribution Generation (DG), it is pertinent that power quality on DG is emphasized. Now, more than ever, advanced technologies are paramount for the reliable and secure operations of power systems. With focus on reactive power management, various means of compensating the system have been discussed, however, technologies with high performance characteristics are achieved using power electronic converters. This has endeared continuous technical advancements to address the new operating challenges being presented today.

\section{REFERENCES}

[1] G. Pepermans, J. Driesen, D. Haeseldonckx, $(2003,08,19)$ "Distributed Generation: Definition, Benefits and Issues".

[2] L. Freris, D. Infield, "Renewable Energy in Power System", A John Wiley \& Sons, 2008, pp. 13-15.

[3] L. Corselli-Nordblad, T. Allen, M. Sturc, "Renewable Energy", Eurostat (2012, 06, 18). Volume (94/2012).

[4] L. Freris, D. Infield, "Renewable Energy in Power System", A John Wiley \& Sons, 2008, pp. 120-122.

[5] A. V. Ferry, "Voltage Control and Voltage Stability of Power Distribution Systems in The Presence of Distributed Generation", 2008, pp. 23

[6] B. M. Weedy, "Electric Power Systems", Second Edition, John Wiley and Sons, London, 1972, page 149.

[7] Tony R. Kuphaldt, "All about circuits", Volume 2. [8] "Static VAR

Compensator", Available: http://en.wikipedia.org/wiki/Static VAR compensator

[9] J. J. Paserba, G. F. Reed, M. Takeda, T. Aritsuka, "FACTS and Customer Power Equipment for the Enhancement of Power Transmission System Performance and Power Quality", Mitsubishi Cooperation, VII SEPOPE, 2000, pp. 1-3. 